\title{
Identification of occult tumors by whole-specimen mapping in solitary papillary thyroid carcinoma
}

\author{
Seog Yun Park ${ }^{1, *}$, Yuh-S Jung, ${ }^{1, *}$ Chang Hwan Ryu, ${ }^{1, *}$, Chang Yoon Lee', You Jin Lee', \\ Eun Kyung Lee', Seok-Ki Kim', Tae Sung Kim', Tae Hyun Kim', Jeyun Jang', \\ Daeyoon Park', Seung Myung Dong ${ }^{3}$, Jae-Goo Kang ${ }^{4}$, Jin Soo Lee ${ }^{2}$ and Junsun Ryu ${ }^{1}$ \\ ${ }^{1}$ Center for Thyroid Cancer, ${ }^{2}$ Center for Lung Cancer, and ${ }^{3}$ Research Institute, National Cancer Center, 323 Ilsan-ro, \\ Ilsandong-gu, Goyang-si, Gyeonggi-do 410-769, Republic of Korea \\ ${ }^{4}$ Department of Otolaryngology-Head and Neck Surgery, National Medical Center, Seoul, Republic of Korea \\ *(S Y Park, Y-S Jung and C H Ryu contributed equally to this work)
}

\author{
Correspondence \\ should be addressed \\ to J Ryu \\ Email \\ jsryu@ncc.re.kr
}

\begin{abstract}
We undertook this study to estimate an accurate incidence and spread patterns of occult papillary thyroid carcinoma (PTC) in patients with a preoperative diagnosis of solitary PTC by using whole-specimen mapping of all specimens after a total thyroidectomy. Enrolled prospectively in this whole-thyroid mapping study are 82 consecutive patients who underwent a total thyroidectomy under a preoperative diagnosis of solitary PTC. All thyroidectomy specimens were serially sectioned in $2 \mathrm{~mm}$ thickness and whole-thyroid mapping was carried out for additional foci of occult PTC. The frequencies of occult lesions detected in the whole and contralateral lobe were determined, and clinicopathologic factors associated with multifocality were assessed. Whole-thyroid mapping revealed 66 occult PTC lesions missed by preoperative ultrasound in $37(45.1 \%)$ of the 82 patients. The great majority $(92.5 \%)$ of the occult PTC was smaller than $3 \mathrm{~mm}$ in size and 25 patients $(30.5 \%)$ had contralateral lesions. We found that the male sex was an independent predictor of multifocality (odds ratio (OR), 3.00; 95\% Cl, 1.11-8.14), adjusting for preoperative findings. Analysis with pathologic parameters showed that the male sex (OR, 5.03; $95 \% \mathrm{Cl}$, 1.68-15.08) and extrathyroidal extensions (OR, 3.03; 95\% Cl, 1.03-8.95) were associated with multifocal PTC. However, none of the clinicopathologic factors evaluated predicted contralateral PTC. Our study demonstrates the diagnostic limitations of ultrasound for the detection of multifocal PTC and the need to consider the possibility of occult lesions in the management of solitary PTC, especially in male patients.
\end{abstract}
Key Words
- thyroid
- papillary thyroid carcinoma
- whole-specimen mapping
- occult
- multifocal

Endocrine-Related Cancer (2015) 22, 679-686

\section{Introduction}

Thyroid cancer is the most common endocrine cancer worldwide, and its incidence is increasing. In 2012, thyroid cancer was the most common malignancy in Korea, with an annual incidence of 87/100 000 people (Jung et al. 2015). Papillary thyroid carcinoma (PTC) comprises $\sim 90 \%$ of all thyroid malignancies and has an excellent prognosis with conventional therapies such as surgery and radioactive iodine therapy.

Despite advances in the understanding of the underlying biological characteristics of PTC and the development of evidence-based guidelines for its treatment, many practical questions remain unanswered. For example, the

Published by Bioscientifica Ltd. 
extent of surgery (lobectomy vs total thyroidectomy) remains controversial. Ultrasonography is currently used in decision-making for the surgical management of PTC. Consensus guidelines recommend that low-risk patients with a small single, node-negative tumor and no extrathyroidal extensions (ETE) should be considered candidates for less extensive surgery, such as lobectomy with or without isthmusectomy (Pacini et al. 2006, Cooper et al. 2009, Perros et al. 2014). However, despite the high resolution of modern ultrasound, which can detect nodules as small as $1-2 \mathrm{~mm}$ (Sakorafas et al. 2005), smaller tumors remain undetected. Furthermore, the ability to detect small malignancies is markedly reduced when diffuse thyroid disease is also present (Park et al. 2013). Therefore, the possibility of multifocal disease in patients for whom only a single nodule was detected by ultrasound is an important issue in the management of PTC, especially in cases of bilateral PTC.

Previous studies have reported multifocality in 18$87 \%$ of the patients with PTC (Katoh et al. 1992, Roti et al. 2008, Lin et al. 2009, Zhao et al. 2013). Although multifocal cancers are thought to be more aggressive, the ramifications of multifocal PTC are unclear because of the differences in the study design and conditions. In particular, multifocal PTC is often not detected because only representative sections are examined in the pathology evaluation, rather than the entire gland.

To determine the optimal surgical management for solitary PTC, as assessed by ultrasound, a better understanding of the incidence and spread pattern of multifocal PTC is needed. Whole-specimen mapping may be useful in answering these questions; however, few studies have described whole-specimen mapping of the thyroid tissue because of time and labor requirements (Katoh et al. 1992). To obtain a more accurate estimate of the incidence and spread patterns of multifocal PTC, we used whole-specimen mapping to examine all specimens after a total thyroidectomy in patients with a preoperative diagnosis of solitary PTC by high-resolution ultrasound and fine-needle aspiration biopsy. In addition, we identified clinicopathologic parameters that may be useful in decision-making regarding the optimal surgical management of PTC.

\section{Materials and methods}

\section{Study patients}

From January to December 2013, 688 consecutive patients with category V (suspicious for malignancy) or VI nodules (PTC), according to the Bethesda System for Reporting

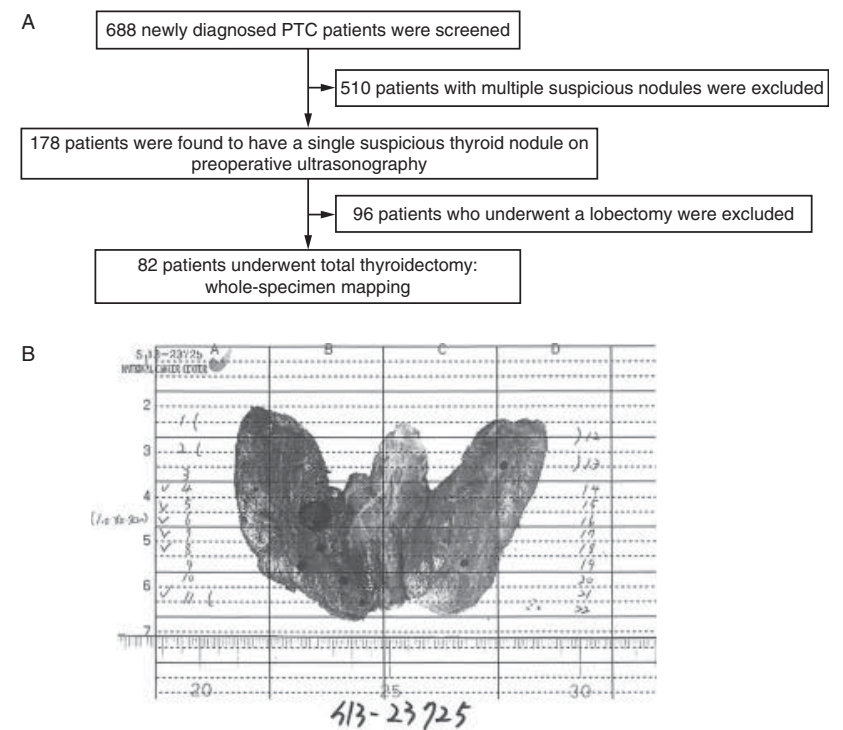

Figure 1

(A) Flow diagram for patient selection. Of the 688 patients screened, 82 were included in the study. (B) The mapping sheet for each patient describes the location, size, and number of nodules.

Thyroid Cytopathology, or the nodules showing mutations in the BRAF gene assessed by PCR-restriction fragment length polymorphism (RFLP) were prospectively screened for the enrollment in this study at the National Cancer Center (Park et al. 2006). Inclusion criteria were i) a single suspicious thyroid nodule on preoperative ultrasound examination and ii) a planned total thyroidectomy. Patients with distant metastasis at initial presentation were excluded. Of 178 patients with a single suspicious thyroid nodule, 82 consecutive patients underwent a total thyroidectomy and are the subject of this study (Fig. 1A). Most of these patients had evidence of clinical T3 stage cancer (ETE) and/or cervical lymph node metastasis on ultrasound $(n=76)$. Included also in this study are six patients who elected to have a total thyroidectomy after being informed about the risks and benefits of this procedure even though they had no visible ETE or cervical lymph node metastasis on ultrasound examination. The study was approved by the Institutional Review Board at the National Cancer Center, Korea (NCCNCS13733). All of the patients were provided written informed consent. The study was conducted in accordance with ethical principles of the Declaration of Helsinki.

\section{Surgical strategy}

The decisions on the extent of surgical resection were made primarily following the guidelines released from

Published by Bioscientifica Ltd. 
the American Thyroid Association and European Thyroid Cancer Taskforce for differentiated thyroid cancer after full interdisciplinary discussion (Pacini et al. 2006, Cooper et al. 2009). Briefly, for patients with a $>1 \mathrm{~cm}$ suspicious nodule such as category V, VI, or BRAF (+), the initial recommended surgical procedure was a total thyroidectomy. For patients who had a $<1 \mathrm{~cm}$ suspicious nodule, we recommended the lobectomy in case of low-risk and intrathyroidal and node-negative PTC. However, if the tumor was suspicious for ETE, involved cervical nodal metastasis, and/or positive family history, we recommended a total thyroidectomy. We also performed the bilateral prophylactic or therapeutic central neck dissection according to clinical circumstances.

\section{Ultrasonographic examination}

All of the patients underwent preoperative ultrasound within 1 month before surgery. All of the ultrasound examinations were performed with a $5-12-\mathrm{MHz}$ linear array transducer (iU22; Philips Healthcare, Eindhoven, The Netherlands) and carried out by a single experienced radiologist (CYL), who performs an average of 8000 thyroid ultrasound examinations annually. A single thyroid nodule was defined as a cytologically suspicious nodule identified by ultrasound without coexisting indeterminate nodules, not including pure cystic nodules and colloid cysts, which cannot become malignant. The definition of the clinical T3, N1, and heterogenecity in ultrasound was described in our previous study (Lee et al. 2014). Briefly, if the echogenicity of the thyroid tissue was moderately heterogeneous with reduced echogenicity compared to the adjacent strap muscles, we defined it as 'heterogeneous' echogenicity. Clinical T3 was defined as capsular abutment or disruption of the perithyroidal echogenic line between the site of thyroid cancer and the thyroid capsule as seen on sonography. We considered a positive lymph node to have increased cortical echogenicity, cystic changes, macrocalcifications or microcalcifications, loss of the fatty hilum, or an indistinct margin with a peripheral halo. All of the ultrasound examinations were recorded, and the movie files were reviewed before the analysis.

\section{Whole-thyroid mapping}

After being fixed in $10 \%$ buffered formalin, the median vertical length of the right and left lobe was $2.7 \mathrm{~cm}$ (range, $1.8-3.9 \mathrm{~cm}$ ) and $2.5 \mathrm{~cm}$ (range, $1.5-4.0 \mathrm{~cm}$ ), respectively. Specimens were horizontally cut into $2 \mathrm{~mm}$ slices and embedded in paraffin. Sections were cut in $4 \mu \mathrm{m}$ thickness from every paraffin block and stained with hematoxylin and eosin for histopathologic examination. One or two sections were mounted in one slide. A mapping sheet was generated for each patient to record the location, size, and number of nodules (Fig. 1B). If the tumor was located in the isthmus, the tumor side was categorized as the more close side of the lobe. The mean number of slides prepared for each patient was 23.7. All of the histologic diagnoses were made by a single pathologist (SYP) according to the recommendations of the World Health Organization.

\section{Statistical analysis}

The primary objective of this study was the estimation of true incidence of multifocal occult PTC in patients who underwent a total thyroidectomy for a solitary PTC lesion diagnosed by ultrasound. Occult PTC means the additional tumor foci detected by whole-thyroid mapping that were undetected by ultrasonography (US). Based on a previous study performed in Korea, which reported that the incidence of occult PTC was $15.8 \%$, we used the occult PTC incidence of $15 \%$ for the null hypothesis. We considered an increased detection rate of 30\% using whole-specimen mapping to be desirable. With a type 1 error of $5 \%$ and a power of $90 \%$, we would therefore need to perform whole-specimen mapping in at least 82 patients. The secondary endpoint was the frequency of occult PTC in the contralateral thyroid.

Logistic regression analyses were performed to i) predict the presence of multifocal PTC in patients diagnosed with solitary PTC before surgery; ii) predict the presence of contralateral disease to plan completion thyroidectomy or follow-up strategies after lobectomy; and iii) predict the clinical behavior of multifocal PTC identified by histology. Covariables (known risk factors for each clinical question) were entered into the multivariable model using a stepwise backward elimination procedure. All of the analyses were performed using the STATA Software version 12.0 (Stata, College Station, TX, USA). All of the reported $P$ values were two-sided; $P<0.05$ was considered significant.

\section{Results}

\section{Clinical characteristics of solitary PTC detected by ultrasound}

Table 1 describes the clinical and pathological characteristics of the study patients: 26 were men and 56 were

Published by Bioscientifica Ltd. 
Table 1 Clinicopathologic characteristics of patients $(n=82)$ with a preoperative diagnosis of solitary papillary thyroid carcinoma (PTC)

\begin{tabular}{l} 
Characteristic \\
\hline Age, years, median (range) \\
Male sex, $n(\%)$ \\
Family history of PTC, $n(\%)$ \\
Ultrasound findings \\
Heterogeneous echogenicity, $n(\%)$ \\
$\mathrm{T}_{3}, n(\%)$ \\
$\mathrm{N} 1, n(\%)$ \\
Pathologic findings \\
Tumor size, mm, median (range) \\
Extrathyroidal extension (pT $\left.\mathrm{p}_{3}\right), n(\%)$ \\
Lymphovascular invasion, $n(\%)$ \\
Blood vessel invasion, $n(\%)$ \\
Lymphocytic thyroiditis, $n(\%)$ \\
Lymph node metastasis, $n(\%)$ \\
BRAF mutation, $n(\%)$
\end{tabular}

\begin{tabular}{c}
\hline Value \\
\hline $44(22-67)$ \\
$26(31.7)$ \\
$6(7.3)$ \\
$18(22.0)$ \\
$73(89.0)$ \\
$26(31.7)$ \\
$7(3-30)$ \\
$52(63.4)$ \\
$35(42.7)$ \\
$6(7.3)$ \\
$37(45.1)$ \\
$38(46.3)$ \\
$52(63.4)$
\end{tabular}

Tumor staging was performed according to the criteria of the 2010 American Joint Committee on Cancer Staging Manual, 7th edition.

women with a median age of 44 years (range 22-67). Of the patients $73(89.0 \%)$ had findings suspicious for ETE, 26 (31.7\%) had findings suspicious for cervical lymph node metastasis on preoperative ultrasound examination, 18 (22.0\%) had heterogeneous echogenicity indicating diffuse thyroid disease, $6(6.3 \%)$ had a positive family history for PTC (first-degree relatives), and 52 (63.4\%) had $B R A F$ mutations. Results of pathologic examination showed that the median tumor size was $7 \mathrm{~mm}$ (range 3-30 $\mathrm{mm}$ ); ETE was detected in 52 patients (63.4\%), cervical lymph node metastasis in 38 patients (46.3\%), and the follicular variant subtype in four patients (4.9\%) (Table 1). Of the 73 patients who were suspicious for ETE in ultrasound, 50 patients $(68.5 \%)$ revealed pathologically proven ETE. Of nine patients who were not suspicious for ETE, two patients (22.2\%) revealed ETE. Of 26 patients showing clinical nodal metastasis in ultrasound, 18 patients $(69.2 \%)$ indicated pathologically proven lymph node metastasis. Of 52 patients with positive $B R A F$ mutation, 22 patients (42.3\%) and 25 patients (48.1\%) showed no ETE and lymph node metastasis, respectively. Of 18 patients showing heterogenous echogenicity, 12 patients (66.7\%) revealed lymphocytic thyroiditis after pathologic examination.

\section{Multifocal papillary carcinoma by whole-specimen mapping}

Of the 82 patients thought to have solitary PTC, as assessed by preoperative ultrasound examination, wholethyroid specimen mapping identified 66 occult PTC lesions in 37 patients (45.1\%). Occult PTC foci were evenly distributed throughout the gland, detected in the ipsilateral lobe in 12 patients (14.6\%), contralateral lobe in 17 patients $(20.7 \%)$, and bilateral lobes in eight patients (9.8\%) (Fig. 2A). The median number of occult PTC lesions was two per patient (range 1-7) (Fig. 2B). Although the size of the occult tumors was $\leq 3 \mathrm{~mm}$ in the great majority (97.0\%) of the patients, larger tumor foci (4-5 $\mathrm{mm}$ ) were detected in two patients with concomitant diffuse thyroid disease (Fig. 2C).

Results of univariate analysis showed that male sex was the only factor significantly associated with

A
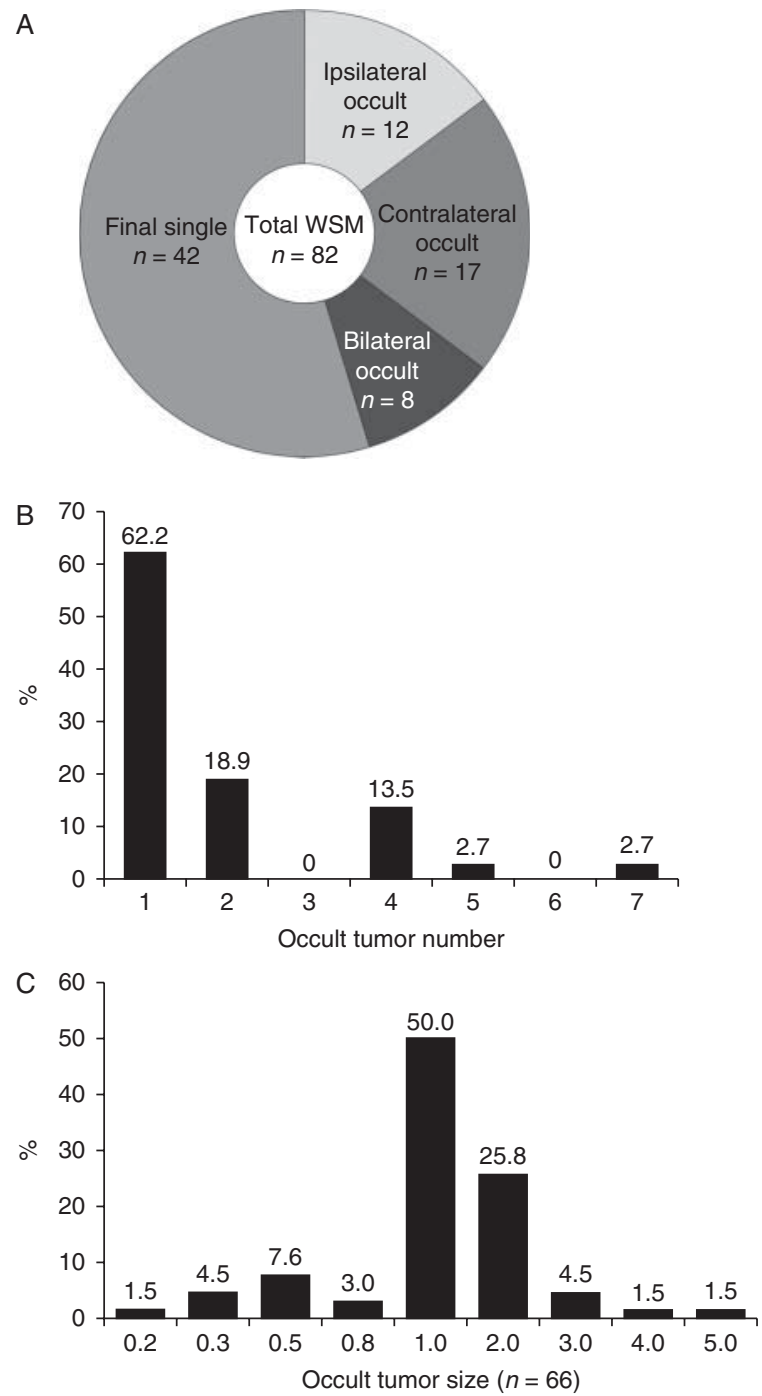

Figure 2

(A) Results of whole-specimen mapping showing the presence and location of occult lesions after diagnosis of solitary papillary thyroid carcinoma (PTC) by ultrasound in 82 patients. (B) Number of occult nodules per patient after diagnosis of solitary PTC by ultrasound. (C) Size of occult tumors in 37 of the 82 patients after diagnosis of solitary PTC by ultrasound.

Published by Bioscientifica Ltd 
multifocal PTC (17/26 (65.4\%) for male vs 20/56 (35.1\%) for female, $P=0.012)$ ). Occult multifocal PTC was not associated with family history or heterogeneous echogenicity on ultrasound. Contralateral multifocal PTC appeared to be inversely associated with clinical T3 stage cancer $(P=0.083)$ but was not associated with regional cervical lymph node metastasis or the presence of ipsilateral multifocal tumors (Table 2).

Results of multivariable analyses confirmed that male sex was a predictor of multifocal PTC after adjusting for age, sex, and preoperative ultrasound findings (e.g., clinical stage T3 or N1, diffuse thyroid disease). The risk of multifocal PTC was approximately three-fold higher for male patients than for female patients (odds ratio (OR), 3.00; 95\% CI, 1.11-8.14) (Table 3). We also performed multivariable analysis to determine whether multifocal PTC was associated with known adverse prognostic factors including age, sex, tumor size, ETE, and cervical lymph node metastasis and found that male sex (OR, 5.03; 95\% CI, 1.68-15.08) and ETE (OR, 3.03; 95\% CI, 1.03-8.95)

Table 2 Results of univariate logistic regression to identify factors associated with bilateral or multifocal papillary thyroid carcinoma (PTC) in patients with a preoperative diagnosis of solitary PTC.

\begin{tabular}{|c|c|c|c|c|c|c|}
\hline \multirow[b]{2}{*}{ Characteristics } & \multirow[b]{2}{*}{$n$} & \multirow[b]{2}{*}{ Single, $\boldsymbol{n}(\%)(n=45)$} & \multicolumn{2}{|c|}{ Multifocality, n (\%) } & \multirow[b]{2}{*}{$P^{*}$} & \multirow[b]{2}{*}{$P^{+}$} \\
\hline & & & All $(n=37)$ & Bilateral $(n=25)$ & & \\
\hline \multicolumn{7}{|l|}{ Age (years) } \\
\hline$<45$ & 41 & $24(58.5)$ & $17(41.5)$ & $11(26.8)$ & \multirow{2}{*}{0.506} & \multirow[t]{2}{*}{0.472} \\
\hline$\geq 45$ & 41 & $21(51.2)$ & $20(48.8)$ & $14(34.1)$ & & \\
\hline \multicolumn{7}{|l|}{ Sex } \\
\hline Female & 56 & $36(64.3)$ & $20(35.7)$ & $14(25.0)$ & \multirow[t]{2}{*}{0.012} & \multirow[t]{2}{*}{0.113} \\
\hline Male & 26 & $9(34.8)$ & $17(65.7)$ & $11(42.3)$ & & \\
\hline \multicolumn{7}{|l|}{ Family history of PTC } \\
\hline No & 76 & 41 (53.9) & $35(46.1)$ & 24 (31.6) & \multirow[t]{2}{*}{0.547} & \multirow[t]{2}{*}{0.445} \\
\hline Yes & 6 & $4(66.7)$ & $2(33.3)$ & $1(16.7)$ & & \\
\hline \multicolumn{7}{|l|}{ Clinical tumor stage } \\
\hline $\mathrm{T} 1$ & 9 & $4(44.4)$ & $5(55.6)$ & $5(55.6)$ & \multirow[t]{2}{*}{0.505} & \multirow[t]{2}{*}{0.083} \\
\hline T3 & 73 & $41(56.2)$ & $32(43.8)$ & $20(27.4)$ & & \\
\hline \multicolumn{7}{|l|}{ Clinical lymph node stage } \\
\hline NO & 56 & $30(53.6)$ & $26(46.4)$ & 19 (33.9) & \multirow[t]{2}{*}{0.727} & \multirow[t]{2}{*}{0.321} \\
\hline N1 & 26 & $15(57.7)$ & $11(42.3)$ & $6(23.1)$ & & \\
\hline \multicolumn{7}{|c|}{ Heterogeneous echogenicity } \\
\hline No & 64 & $32(50.0)$ & $32(50.0)$ & $20(31.2)$ & \multirow[t]{2}{*}{0.094} & \multirow[t]{2}{*}{0.777} \\
\hline Yes & 18 & $13(72.2)$ & $5(27.8)$ & $5(27.8)$ & & \\
\hline Tumor size & & & & & & \\
\hline$\leq 1 \mathrm{~cm}$ & 56 & $31(55.4)$ & $25(44.6)$ & $15(26.8)$ & 0.898 & 0.285 \\
\hline$>1 \mathrm{~cm}$ & 26 & $14(53.8)$ & $12(46.2)$ & $10(38.5)$ & & \\
\hline Extrathyroidal extensior & & & & & & \\
\hline No & 30 & $19(63.3)$ & $11(36.7)$ & $9(30.0)$ & 0.243 & 0.942 \\
\hline Yes & 52 & $26(50.0)$ & $26(50.0)$ & $16(30.8)$ & & \\
\hline Lymphovascular invasio & & & & & & \\
\hline No & 47 & $25(53.2)$ & $22(46.8)$ & 15 (31.9) & 0.823 & 0.745 \\
\hline Yes & 35 & $20(57.1)$ & $15(42.9)$ & $10(28.6)$ & & \\
\hline Blood vessel invasion & & & & & & \\
\hline No & 76 & $43(56.6)$ & $33(43.4)$ & $23(30.3)$ & 0.271 & 0.875 \\
\hline Yes & 6 & $2(33.3)$ & $4(66.7)$ & $2(33.3)$ & & \\
\hline Lymphocytic thyroiditis & & & & & & \\
\hline No & 45 & $24(53.3)$ & $21(46.7)$ & $14(31.1)$ & 0.757 & 0.892 \\
\hline Yes & 37 & $21(56.8)$ & $16(43.2)$ & $10(26.3)$ & & \\
\hline Lymph node metastasis & & & & & & \\
\hline Negative & 44 & $21(47.7)$ & $23(52.3)$ & $15(34.1)$ & 0.161 & 0.446 \\
\hline Positive & 38 & $24(63.2)$ & $14(36.8)$ & $10(26.3)$ & & \\
\hline$B R A F$ mutation status & & & & & & \\
\hline Equivocal or negative & 30 & $14(46.7)$ & $16(53.2)$ & $10(33.3)$ & 0.256 & 0.671 \\
\hline Positive & 52 & $31(59.6)$ & $21(56.8)$ & $15(28.8)$ & & \\
\hline Ipsilateral multifocal PT & & & & & & \\
\hline No & 62 & & & $17(27.4)$ & & 0.288 \\
\hline Yes & 20 & & & $8(40.0)$ & & \\
\hline
\end{tabular}

${ }^{\star} P, P$ value with multifocal $\mathrm{PTC} ;{ }^{\dagger} P, P$ value with bilateral PTC.

http://erc.endocrinology-journals.org DOI: $10.1530 /$ ERC-15-0152
(C) 2015 Society for Endocrinology Printed in Great Britain 
Table 3 Results of multivariable analysis to determine preoperative predictors of multifocal papillary thyroid carcinoma (PTC) and its association with adverse prognostic factors

\begin{tabular}{|c|c|c|}
\hline Variables & OR $(95 \% \mathrm{Cl})$ & $\boldsymbol{P}$ \\
\hline \multicolumn{3}{|l|}{ Prediction of multifocal PTC ${ }^{a}$} \\
\hline Male sex & $3.00(1.11-8.14)$ & 0.031 \\
\hline Heterogeneous echogenicity & $0.50(0.15-1.63)$ & 0.251 \\
\hline \multicolumn{3}{|l|}{$\begin{array}{l}\text { Association with adverse } \\
\text { prognostic factors }{ }^{b}\end{array}$} \\
\hline Male sex & $5.03(1.68-15.08)$ & 0.004 \\
\hline Extrathyroidal extension & $3.03(1.03-8.95)$ & 0.044 \\
\hline Lymph node metastasis & $0.38(0.14-1.03)$ & 0.057 \\
\hline \multicolumn{3}{|l|}{ Prediction of bilateral PTC ${ }^{\mathrm{C}}$} \\
\hline Extrathyroidal extension & $0.30(0.07-1.24)$ & 0.096 \\
\hline
\end{tabular}

Logistic regression analysis with stepwise backward elimination was used for each analysis.

${ }^{a}$ Multivariable analysis was adjusted for age, sex, and suspicious ultrasound findings such as $\mathrm{T} 3, \mathrm{~N} 1$, and heterogeneous echogenicity.

${ }^{b}$ Multivariable analysis was adjusted for age, sex, tumor size, extrathyroidal extensions, and cervical lymph node metastasis.

'Multivariable analysis was adjusted for extrathyroidal extensions, ipsilateral multifocal disease, and cervical lymph node metastasis.

correlated positively with multifocal PTC. However, results of multivariable analyses to identify risk factors for contralateral multifocal PTC after adjusting for clinical T3 stage cancer, presence of occult ipsilateral tumors, and cervical lymph node metastasis showed that none of the factors evaluated was associated with bilateral PTC in these patients (Table 3).

\section{Discussion}

Recent guidelines recommend a total thyroidectomy if the patients have a family history, a history of radiation exposure or evidence of clinical or radiological locoregional extension (T3-4a, or N1) and lobectomy for low-risk patients with single, node-negative tumors without ETE on preoperative evaluation. Currently, ultrasonography is the first-line decision-making tool for the surgical management of PTC (Pacini et al. 2006, Cooper et al. 2009, Perros et al.2014). Some surgeons opt for a lobectomy as the initial therapy for sonographic solitary PTC. This is a critical decision because the extent of the initial surgery sets the stage for subsequent adjunctive therapy. While many patients who are treated with a lobectomy may carry the potential risk of undertreatment (e.g., morbidity related to persistent/recurrent disease), some patients who underwent a total thyroidectomy may suffer from serious complications of extensive surgery (e.g., bilateral vocal cord palsy, hypoparathyroidism). Recent studies have revealed that multifocality of PTC is a common phenomenon and is increasingly considered as an important predictor of aggressive behavior and poor prognosis (Lin et al. 2009, Roti et al. 2008, Zhao et al. 2013). It is important to identify patients at high risk for recurrence, who will clearly benefit from a more extensive treatment.

In this study, we used whole-thyroid mapping in an attempt to determine the prevalence and distribution pattern of occult multifocal PTC in a cohort of 82 consecutive patients with a solitary nodule found on preoperative ultrasound examination. Our study revealed that $45.1 \%$ of those preoperatively diagnosed as solitary PTC had occult multifocal tumors, most of which were $\leq 3 \mathrm{~mm}$ in size; however, larger tumors $(4-5 \mathrm{~mm})$ were missed in two patients, showing heterogeneous echogenicity associated with diffuse thyroid disease. The number of multifocal lesions may have been greater than observation because sections were obtained every $2 \mathrm{~mm}$; theoretically, occult carcinoma sized $<2 \mathrm{~mm}$ could have been missed. Thus, the number of these lesions may have been also greater. These findings reflect the current limitations of ultrasound technology in the detection of small foci other than the index lesion. Mapping of the entire thyroid gland of patients with PTC was first described in 1992 (Katoh et al. 1992). They reported that multifocal PTC was $78.1 \%$, which was a higher prevalence than the result of this study. This might be due to the differences of the enrolled patients and diagnostic tools for the detection of PTC. Previous reports did not prospectively enroll the patients nor control the patient tumor status (solitary nodule). Also, their report was performed in the pre-sonographic era when the diagnosis was mainly made by palpation. The meaning of 'occult' was completely different in this study.

In our study, the occult multifocal tumors were evenly distributed throughout the gland and localized to the contralateral lobe in $25(30.5 \%)$ of the 82 patients, indicating that the presence of bilateral disease would have been missed in $\sim 30 \%$ of the patients if surgery removed only the ipsilateral lobe. Several studies have reported a substantial reservoir of small $(<3-5 \mathrm{~mm})$ occult PTC nodules in the general population that never progress into clinically overt disease (Harach et al. 1985, Yamamoto et al. 1990). In addition, excellent outcomes can be achieved with a lobectomy (Vaisman et al. 2011, Lee et al. 2013, Nixon et al. 2012). Therefore, our findings cannot justify total thyroidectomy for all of the patients with solitary PTC on ultrasound. However, because the patients in our series had clinically advanced PTC, some of the occult nodules could be the source of recurrence, reported as multiple synchronous tumors or intrathyroidal metastasis (Mazzaferri \& Jhiang 1994, Hay et al. 2002, Bilimoria et al. 2007, Iacobone et al. 2014).

Published by Bioscientifica Ltd. 
Problems inherent to current diagnostic modalities (ultrasound and fine-needle aspiration cytology) complicate decisions regarding the extent of the initial thyroid surgery and underscore the need to identify clinicopathologic parameters predictive of multifocal disease. In this study, only male sex was an independent predictor of multifocal PTC; age, family history, and ultrasound findings (e.g., size, ETE of the index tumor, and lymph node metastasis) showed no predictive value for multifocality. Male predominance in multifocal PTC has been reported by other studies but remains controversial. Among the studies using whole-specimen mapping, two autopsy series reported male predominance in multifocal PTC (Harach et al. 1985, Yamamoto et al. 1990); however, a clinical study found no predilection in terms of sex (Mazeh et al. 2011). Regarding pathologic parameters, index tumor size and lymph node metastasis were not associated with multifocality in univariate or multivariable analyses. Although the presence of ETE appeared to correlate with multifocality, male sex was the only significant independent predictor of multifocality.

A previous study suggested the completion of a thyroidectomy for patients with ipsilateral multifocality (Pitt et al. 2009). However, we found that the risk of occult contralateral nodules in patients with ipsilateral multifocal PTC did not differ significantly from that of patients without ipsilateral multifocal PTC.

In retrospect, we face the reality that, even in the patients who were candidates for a total thyroidectomy, almost $70 \%$ of the patients enrolled in this study could have been treated with a lobectomy alone. Unfortunately, however, we do not have good predictive marker(s) for multifocal PTC. Nevertheless, genuine efforts should be exercised to inform all of the potential candidates about the risks and benefits associated with a total thyroidectomy.

A potential limitation of our study is that, because of ethical issues, we did not include all of the patients whose ultrasound findings indicated solitary PTC. This study included 76 patients with ETE and/or nodal metastasis and six patients without clinical ETE or nodal metastasis. The former may have more aggressive biological behavior compared to the latter, low risk patients (Pacini et al. 2006, Cooper et al. 2009, Park et al. 2009, Lee et al. 2014). Therefore, the rate of multifocal PTC may be different in all solitary PTC.

In summary, our study demonstrates the current limitations in detecting multifocal PTC by ultrasound or conventional pathologic examination. Occult multifocal tumors are frequently observed after the diagnosis of solitary PTC by ultrasound. Our study also found that multifocal PTC is associated with the male sex and ETE. Further investigation based on a large-scale prospective mapping of the entire thyroid gland is needed to confirm our results. Furthermore, until the natural history of PTC is clarified, caution should be used when considering male sex as an indicator of a poor prognosis after detection of a small PTC nodule.

Declaration of interest

The authors declare that there is no conflict of interest that could be perceived as prejudicing the impartiality of the research reported.

\section{Funding}

This work was supported by a National Cancer Center Grant, Korea (grant number NCC-1310350).

\section{Author contribution statement}

SY Park, Y-S Jung, C H Ryu, CY Lee, and J Ryu were involved in data collection. SY Park, Y-S Jung, C H Ryu, CY Lee, Y J Lee, E K Lee, S-K Kim, T S Kim, T H Kim, J Jang, D Park, S M Dong, J S Lee, and J Ryu were involved in data analysis. S Y Park, Y-S Jung, C H Ryu, J-G Kang, and J Ryu wrote the manuscript. All of the authors participated in data interpretation and revision and finalization of the report for submission. All authors meet the International Committee of Medical Journal Editors (ICMJE) criteria for authorship.

\section{Acknowledgements}

We thank the National Cancer Center investigators and staff. Most importantly, we thank the study patient for their contributions that made this study possible.

\section{References}

Bilimoria KY, Bentrem DJ, Ko CY, Stewart AK, Winchester DP, Talamonti MS \& Sturgeon C 2007 Extent of surgery affects survival for papillary thyroid cancer. Annals of Surgery 246 375-384. (doi:10.1097/ SLA.0b013e31814697d9)

Cooper DS, Doherty GM, Haugen BR, Kloos RT, Lee SL, Mandel SJ, Mazzaferri EL, McIver B, Pacini F, Schlumberger M et al. 2009 Revised American Thyroid Association management guidelines for patients with thyroid nodules and differentiated thyroid cancer. Thyroid 19 1167-1214. (doi:10.1089/thy.2009.0110)

Harach HR, Franssila KO \& Wasenius VM 1985 Occult papillary carcinoma of the thyroid. A "normal" finding in Finland. A systematic autopsy study. Cancer 56 531-538. (doi:10.1002/1097-0142(19850801)56:3< 531::AID-CNCR2820560321>3.0.CO;2-3)

Hay ID, Thompson GB, Grant CS, Bergstralh EJ, Dvorak CE, Gorman CA, Maurer MS, McIver B, Mullan BP, Oberg AL et al. 2002 Papillary thyroid carcinoma managed at the Mayo Clinic during Six decades (19401999): temporal trends in initial therapy and long-term outcome in 2444 consecutively treated patients. World Journal of Surgery 26 879-885. (doi:10.1007/s00268-002-6612-1)

Iacobone M, Jansson S, Barczyński M \& Goretzki P 2014 Multifocal papillary thyroid carcinoma - a consensus report of the European 
Society of Endocrine Surgeons (ESES). Langenbeck's Archives of Surgery 399 141-154. (doi:10.1007/s00423-013-1145-7)

Jung K, Won Y, Kong H, Oh C, Lee JY, Cho H, Lee DH \& Lee KH 2015 Cancer statistics in Korea: incidence, mortality, survival, and prevalence in 2012. Cancer Research and Treatment 47 127-141. (doi:10.4143/crt.2015.060)

Katoh R, Sasaki J, Kurihara H, Suzuki K, Iida Y \& Kawaoi A 1992 Multiple thyroid involvement (intraglandular metastasis) in papillary thyroid carcinoma. A clinicopathologic study of 105 consecutive patients. Cancer 70 1585-1590. (doi:10.1002/1097-0142(19920915) 70:6<1585::AID-CNCR2820700623>3.0.CO;2-Z)

Lee J, Park JH, Lee CR, Chung WY \& Park CS 2013 Long-term outcomes of total thyroidectomy versus thyroid lobectomy for papillary thyroid microcarcinoma: comparative analysis after propensity score matching. Thyroid 23 1408-1415. (doi:10.1089/thy.2012.0463)

Lee CY, Kim SJ, Ko KR, Chung K \& Lee J 2014 Predictive factors for extrathyroidal extension of papillary thyroid carcinoma based on preoperative sonography. Journal of Ultrasound in Medicine 33 231-238. (doi:10.7863/ultra.33.2.231)

Lin JD, Chao TC, Hsueh C \& Kuo SF 2009 High recurrent rate of multicentric papillary thyroid carcinoma. Annals of Surgical Oncology 16 2609-2616. (doi:10.1245/s10434-009-0565-7)

Mazeh H, Samet Y, Hochstein D, Mizrahi I, Ariel I, Eid A \& Freund HR 2011 Multifocality in well-differentiated thyroid carcinomas calls for total thyroidectomy. American Journal of Surgery 201 770-775. (doi:10.1016/ j.amjsurg.2010.03.004)

Mazzaferri EL \& Jhiang SM 1994 Long-term impact of initial surgical and medical therapy on papillary and follicular thyroid cancer. American Journal of Medicine 97 418-428. (doi:10.1016/0002-9343 (94)90321-2)

Nixon IJ, Ganly I, Patel SG, Palmer FL, Whitcher MM, Tuttle RM, Shaha A \& Shah JP 2012 Thyroid lobectomy for treatment of well differentiated intrathyroid malignancy. Surgery 151 571-579. (doi:10.1016/j.surg. 2011.08.016)

Pacini F, Schlumberger M, Dralle H, Elisei R, Smit JW, Wiersinga W \& European Thyroid Cancer Taskforce 2006 European consensus for the management of patients with differentiated thyroid carcinoma of the follicular epithelium. European Journal of Endocrinology 154 787-803. (doi:10.1530/eje.1.02158)
Park SY, Park YJ, Lee YJ, Lee HS, Choi SH, Choe G, Jang H-C, Park SH, Park DJ \& Cho BY 2006 Analysis of differential BRAF(V600E) mutational status in multifocal papillary thyroid carcinoma: evidence of independent clonal origin in distinct tumor foci. Cancer 107 1831-1838. (doi:10.1002/cncr.22218)

Park JS, Son K-R, Na DG, Kim E \& Kim S 2009 Performance of preoperative sonographic staging of papillary thyroid carcinoma based on the sixth edition of the AJCC/UICC TNM classification system. AJR. American Journal of Roentgenology 192 66-72. (doi:10.2214/AJR.07.3731)

Park M, Park SH, Kim EK, Yoon JH, Moon HJ, Lee HS \& Kwak JY 2013 Heterogeneous echogenicity of the underlying thyroid parenchyma: how does this affect the analysis of a thyroid nodule? BMC Cancer $\mathbf{1 3}$ 550. (doi:10.1186/1471-2407-13-550)

Perros P, Boelaert K, Colley S, Evans C, Evans RM, Gerrard Ba G, Gilbert J, Harrison B, Johnson SJ, Giles TE et al. 2014 Guidelines for the management of thyroid cancer. Clinical Endocrinology 81 (Suppl 1) 1-122. (doi:10.1111/cen.12515)

Pitt SC, Sippel RS \& Chen H 2009 Contralateral papillary thyroid cancer: does size matter? American Journal of Surgery 197 342-347. (doi:10.1016/ j.amjsurg.2008.09.011)

Roti E, degli Uberti EC, Bondanelli M \& Braverman LE 2008 Thyroid papillary microcarcinoma: a descriptive and meta-analysis study. European Journal of Endocrinology 159 659-673. (doi:10.1530/EJE-07-0896)

Sakorafas GH, Giotakis J \& Stafyla V 2005 Papillary thyroid microcarcinoma: a surgical perspective. Cancer Treatment Reviews 31 423-438. (doi:10.1016/j.ctrv.2005.04.009)

Vaisman F, Shaha A, Fish S \& Michael Tuttle R 2011 Initial therapy with either thyroid lobectomy or total thyroidectomy without radioactive iodine remnant ablation is associated with very low rates of structural disease recurrence in properly selected patients with differentiated thyroid cancer. Clinical Endocrinology 75 112-119. (doi:10.1111/j.13652265.2011.04002.x)

Yamamoto Y, Maeda T, Izumi K \& Otsuka H 1990 Occult papillary carcinoma of the thyroid. A study of 408 autopsy cases. Cancer $\mathbf{6 5}$ 1173-1179. (doi:10.1002/1097-0142(19900301)65:5 < 1173::AIDCNCR2820650524>3.0.CO;2-2)

Zhao Q, Ming J, Liu C, Shi L, Xu X, Nie X \& Huang T 2013 Multifocality and total tumor diameter predict central neck lymph node metastases in papillary thyroid microcarcinoma. Annals of Surgical Oncology 20 746-752. (doi:10.1245/s10434-012-2654-2)

Received in final form 24 June 2015

Accepted 24 June 2015

Made available online as an Accepted Preprint

25 June 2015 http://erc.endocrinology-journals.org DOI: 10.1530/ERC-15-0152
(C) 2015 Society for Endocrinology Printed in Great Britain 